\title{
Temporal development of stem rot caused by Athelia rolfsii in peanut fields in Iran
}

\author{
Gh.A. Amirkyaei ${ }^{1}$, S. Mousanejad ${ }^{1 *}$, N. Safaie ${ }^{2}$ and S.A. Khodaparast ${ }^{1}$
}

Summary Stem rot caused by Athelia rolfsii (syn. Sclerotium rolfsii), is an important disease of peanut in Iran. Soil samples were collected from 15 peanut fields before the 2014 growing season in Guilan province, Iran and the viable sclerotia were counted using the soil-tray technique. The 15 selected fields were also evaluated for disease incidence at three intervals during the growing seasons of 2013 and 2014. The disease incidence at the end of the growing season ranged from 0 to $29.3 \%$ and from 0 to $45 \%$ in 2013 and 2014, respectively, depending on the field. The disease progress model, which was introduced for each field based on the disease incidence, showed good fitness with the monomolecular model in both years, but especially in 2014. Disease severity was evaluated in three out of the 15 peanut fields at three intervals during the growing season of 2014. The monomolecular model could describe more than $88 \%$ of the data. There was a significant linear relationship between the disease incidence or severity at the end of the growing season and the inoculum density in the soil. A positive linear relationship was also observed between the disease progress rate and the inoculum density.

Additional keywords: Arachis hypogaea, Sclerotium rolfsii, southern blight, temporal analysis, viable sclerotia, white rot

\section{Introduction}

Groundnut or peanut (Arachis hypogaea L.) as an annual legume crop is cultivated in more than 80 countries in the tropics, subtropics and warm temperate locations (Hammons, 1994). It is a main source of edible oil, vitamins and amino acids and is extensively used for feed and food (Savage and Keenan, 1994). Groundnut is also a main crop in Guilan province of Iran with about 3500 hectares cultivation area.

Southern blight, stem rot or white rot, caused by Athelia rolfsii (Curzi) Tu and Kimbrough (syn: Sclerotium rolfsii Sacc.), is an important disease of peanut. The disease is found in all peanut-growing areas worldwide, where it causes great yield losses (up to $80 \%$ ), especially when the disease incidence is high and the edaphic conditions, such as soil tem-

\footnotetext{
1 Department of Plant Protection, Faculty of Agricultural Sciences, University of Guilan, P.O. Box: 41635-1314, Rasht, Iran.

2 Department of Plant Pathology, College of Agriculture, Tarbiat Modares University, P.O. Box: 14115-336, Tehran, Iran.

* Corresponding author: mousanejad@guilan.ac.ir smousanejad@yahoo.com
}

perature and humidity, are favorable for fungal development (Kolte, 1984; Kokalis-Burelle et al., 1997; Le, 2004; Nguyen et al., 2004).

Athelia rolfsii is one of the most common soil-borne plant pathogenic fungi in warm temperate and subtropical regions of the world. More than 500 plant species, mostly dicotyledonous, are hosts of the pathogen (Punja et al., 1985). Several symptoms are produced by $A$. rolfsii on its hosts, such as crown and root rot, stem canker and damping-off with the resulting diseases being called southern wilt, blight or stem rot (Punja, 1985). Yield losses were reported between 10 and $25 \%$ and in some cases even more than 81\% (Mehan et al., 1995).

Athelia rolfsii overwinters in soil and infected plant tissues as mycelium or sclerotia. Germinating sclerotia or hyphae infect the plant under favorable conditions and then colonize and invade the root and stem tissues through its typical silky white mycelium (Mullen, 2001). Infected plants become yellow and then wilt; the collar root turns brown and rots. In groundnut, $A$. rolfsii also infects the pegs and pods leading to high yield losses. Control of $A$. rolfsii is difficult by physical and cultural practices because of its 
wide host range (Aycock, 1966; Punja, 1985) and persistent sclerotia (Punja, 1985; Lakpale, 2007). Knowledge of the disease epidemiology, especially temporal analysis of the disease and its relationship with the inoculum density, is essential to successfully implement management practices (e.g., chemical and biological).

Stem rot incidence has been mostly considered in studies on the pathogenicity of fungal isolates or as a tool for assaying resistant lines or cultivars. However, only a few precise studies exist on the progression of the disease under field conditions. Backman et al. (1981) developed regression equations to relate populations of viable sclerotia to the percentage of sugar beet roots infected by A. rolfsii. Punja (1986) studied the stem rot incidence and its progression on processing carrots in naturally infested fields in Georgia and North Carolina and reported that the disease increased almost linearly until harvest time with the final incidence ranging $39-48 \%$. In addition, there was a significant correlation between the percentage of dead plants and inoculum density up to 15 sclerotia / $300 \mathrm{~cm}^{3}$ dried soil. Tomasino and Conway (1987) observed a positive linear relationship between sclerotial densities and disease incidence in apple nurseries in Oklahoma. Okabe and Matsumoto (2000) reported that $10-40 \%$ of the peanut plants in four fields in Tsukuba, Japan, were infected by $A$. rolfsii. Le et al. (2012) investigated the stem rot incidence in eight groundnut-growing areas in central Vietnam and showed that $5-25 \%$ of the groundnut plants were infected by $A$. rolfsii.

The stem rot severity has been assessed on various hosts mainly for screening cultivars for resistance in breeding programs and not for studying the disease progress under filed conditions. Shokes and Gorbet (1998) evaluated the resistance of 11 peanut genotypes to stem rot disease at the North Florida Research and Education Center (NFREC) in 1991-1993 using an agar disk inoculation method and a 1-6 scale for assessing disease severity. Fery and Dukes $(2005 ; 2011)$ determined the resistance of some pepper and cowpea cultivars and lines to stem rot based on the disease severity. Eslami et al. (2015) also evaluated some peanut genotypes for resistance to $A$. rolfsii based on the disease severity.

The aim of the current study was to determine the temporal progress of stem rot and its correlation with the inoculum density in the peanut fields of Astaneh-Ashrafiyeh county in Guilan province, which is the main peanut cultivation area in Iran. The results will contribute to better management of the disease and the reduction of yield losses.

\section{Materials and Methods}

\section{Determination of soil inoculum density}

Fifteen peanut fields in different locations of Astaneh-Ashrafiyeh county were selected based on the history of stem rot disease. In one of the fields (field 7), two main hosts of $A$. rolfsii, bean and peanut, were cultivated simultaneously. Selected fields were divided into $250-500 \mathrm{~m}^{2}$ plots. In 2014 and before the growing season, 10 soil core samples $15 \mathrm{~cm}$ deep and $7 \mathrm{~cm}$ wide were randomly collected from each plot (Punja et al., 1985) and transferred to the laboratory. The number of viable sclerotia in each soil sample was determined using the soil-tray technique (Rodriguez-Kabana et al., 1980).

\section{Evaluation of the disease parameters}

During the 2013 and 2014 growing seasons, the plots of the 15 selected fields were monitored for disease symptoms. Thirty randomly selected plants in each plot were evaluated and disease incidence was estimated as the percentage of infected plants per plot. The plant which either showed stem lesions covered with white mycelium and sclerotia or was associated with the presence of sclerotia on the soil surface around the stem base was recorded as infected plant. In total 222 plots were surveyed. This evaluation was done at three intervals during the growing season. Final recording was done at harvest. The mean disease incidence in each evaluation time point was calculated for each field. 
In 2014, three peanut fields (fields 2, 6 and 7) of 0.6-0.9 ha each in Noghredeh village in Astaneh-Ashrafiyeh county were selected for evaluating the disease severity. In total, 43 plots and 30 plants in each plot were evaluated. Disease severity was recorded for all the stems of each evaluated plant based on the presence or absence of symptoms on stems, stem area affected (percentage of stem circumference which was surrounded by lesions) and mycelium outgrowth on the lesions, as introduced by Le et al. (2012) with some modifications (Table 1). Subsequent$l y$, the mean disease severity was calculated for each plant and plot. This evaluation was done at three intervals during the growing season of 2014, except for field 7 where only two assessments were done, because the crop was harvested earlier than in the other two fields. density were determined using Statgraphics v. 2.1.

\section{Results}

\section{Soil inoculum density}

In 2014, a total of 203 soil samples from the 15 selected peanut fields were analyzed for viable sclerotia using the soil-tray technique. Mycelia resulted from germination of viable sclerotia (Fig. 1) were observed in 20 soil samples from 8 peanut fields, with the lowest and the highest numbers of viable sclerotia being recorded in fields 6 and 1, respectively (Table 2).

\section{Symptom development}

All studied fields showed disease symptoms except for field 10 which had zero dis-

Table 1. Characteristics used to evaluate the stem rot severity caused by Athelia rolfsii in peanut plants.

\begin{tabular}{l|c|c|c|c}
\hline Scale & Stem area affected (\%) & $\begin{array}{c}\text { Mycelium outgrowth on the } \\
\text { lesions }\end{array}$ & Stem appearance & Severity \\
\hline 0 & $0 \%$ & No & Healthy & 0 \\
1 & $>0-15 \%$ & No & Healthy & $10 \%$ \\
2 & $16-30 \%$ & Ho or Yes & Healthy & $25 \%$ \\
3 & $31-60 \%$ & Yes & Partially wilted & $60 \%$ \\
4 & $61-75 \%$ & Yes & Partially wilted & $75 \%$ \\
5 & $76-99 \%$ & Yes & Dead & $100 \%$ \\
\hline
\end{tabular}

\section{Statistical analysis}

Linearized disease progress curves were drawn for each of the evaluated fields based on the disease incidence or severity using Excel software. For the temporal analysis of the disease, the monomolecular growth model $\ln [1 /(1-y)]=r_{m} t+C$, in which, $y$ is the disease incidence or severity at time $t, r_{m}$ is the disease growth rate and $C$ is $y$-intercept and equal to $\ln \left[1 /\left(1-y_{0}\right)\right]$ when $t=0$, fitted with the incidence and severity data using Statgraphics v. 2.1. The relationship between the disease incidence or severity and the inoculum density as well as the relationship between the growth rate and the inoculum

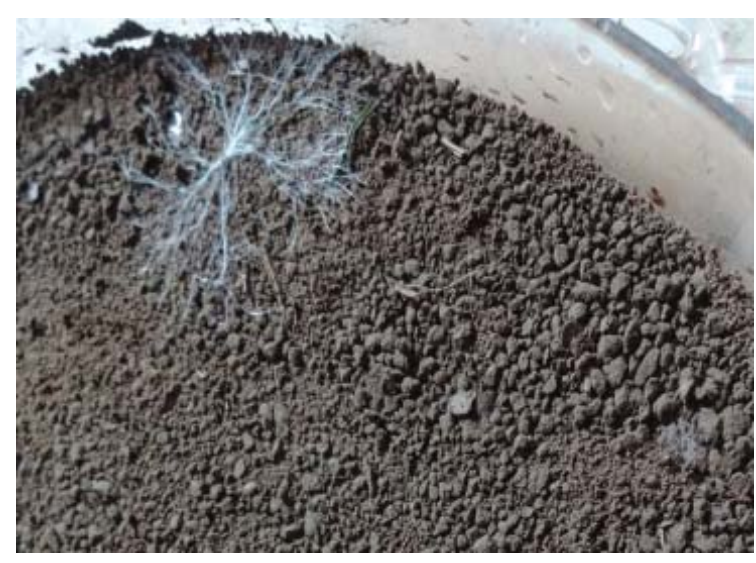

Figure 1. Germination of a viable sclerotium of Athelia rolfsii and mycelia formation on the soil surface using the soil-tray technique. 
ease incidence in both years. The mean disease incidence at harvest time in the 15 studied fields ranged between 0 and 29.3\% and between 0 and 45\% in 2013 and 2014, respectively (Fig. 2, Fig. 3). The mean disease incidence at the beginning of the growing season in 2014 was $0.65 \%$ higher than that in 2013. Also, the mean disease incidence at the second evaluation time point (middle of the growing season when the plants were at anthesis stage) in 2014 was $1.64 \%$ higher than that in 2013. The final mean disease incidence at harvest time was approximately the same in 2013 (12.88\%) and 2014 (12.90\%),

Table 2. Number of viable Athelia rolfsii sclerotia in soil samples collected from peanut fields in Astaneh-Ashrafiyeh county, Iran in 2014 and the respective stem rot incidence in those fields at harvest.

\begin{tabular}{l|c|c|c|c}
\hline Field No & Area (ha) & Size of soil sample $(\mathrm{g})$ & Number of viable sclerotia / 500 g soil & Disease incidence (\%) \\
\hline 1 & 1 & 1000 & 4 & 45 \\
2 & 0.6 & 500 & 2 & 25.66 \\
3 & 0.7 & 1050 & 1.5 & 17.10 \\
4 & 1.5 & 1450 & 1.3 & 14.48 \\
5 & 0.8 & 800 & 0.625 & 11.16 \\
6 & 0.9 & 900 & 0.45 & 11.48 \\
7 & 1.2 & 1100 & 0.55 & 12.87 \\
8 & 0.7 & 500 & 2 & 10 \\
\hline
\end{tabular}
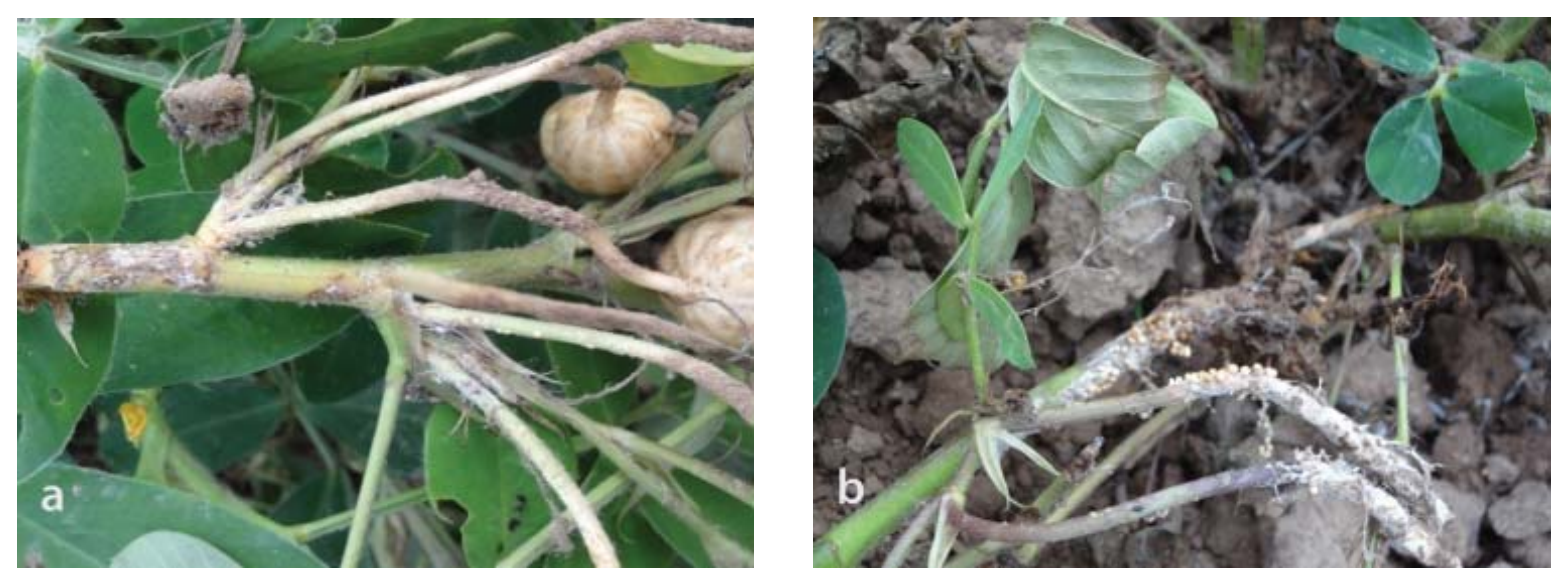

Figure 2. Symptoms (lesions, cankers) and sclerotia of Athelia rolfsii on peanut stems (a) and gynophores (b).
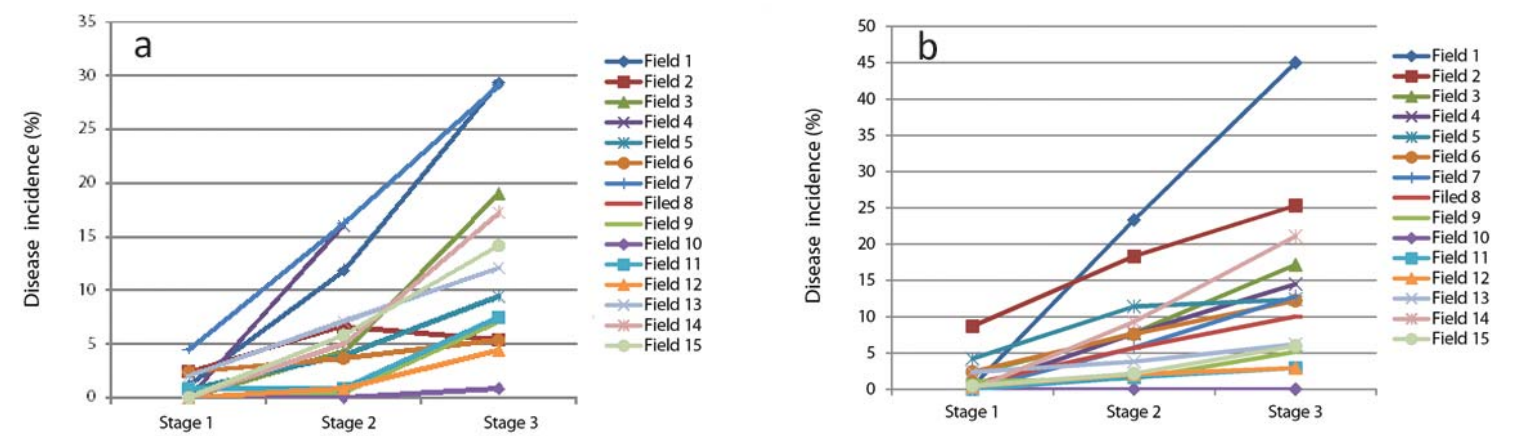

Figure 3. Stem rot disease progress in each evaluated peanut field based on the incidence data in 2013 (a) and 2014 (b). Stage 1: Beginning of the growing season; Stage 2: Middle of the growing season (anthesis stage); Stage 3: Harvest time. 
although the final evaluation in 2014 was done 8 days earlier than in 2013.

Modeling the disease incidence progress in 2014 for the plots of 8 out of the 15 experimental fields (Fig. 4) showed that the disease progress had good fitness $(\geq 90 \%)$ with the monomolecular model in more than $65 \%$ of the plots, while ignoring the plots with zero incidence (Table 3 and Fig. 4). The disease progress model was also introduced for each field based on the mean
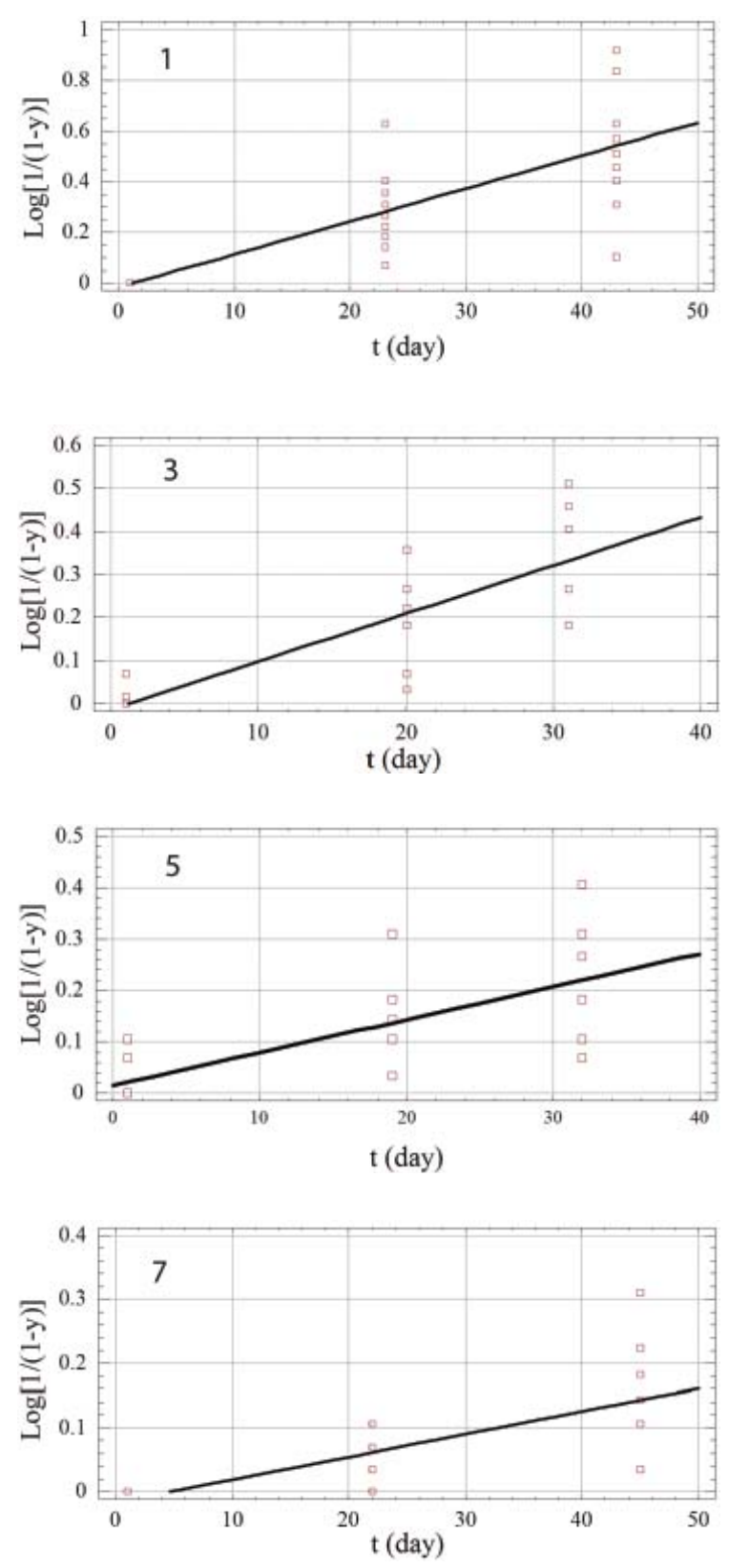

of incidence in the plots in each evaluation time point in 2013 and 2014 (Table 4) and again the data showed good fitness with the monomolecular model in both years, but especially in 2014 . The disease growth rate in seven fields (fields 1, 2, 3, 5, 6, 8 and 14) was higher in 2014 than in 2013, whereas in the other six fields, the growth rate in 2014 was lower than that in 2013 (Table 4). In field 4, the third evaluation was not done in 2013 because the crop was harvested earli-
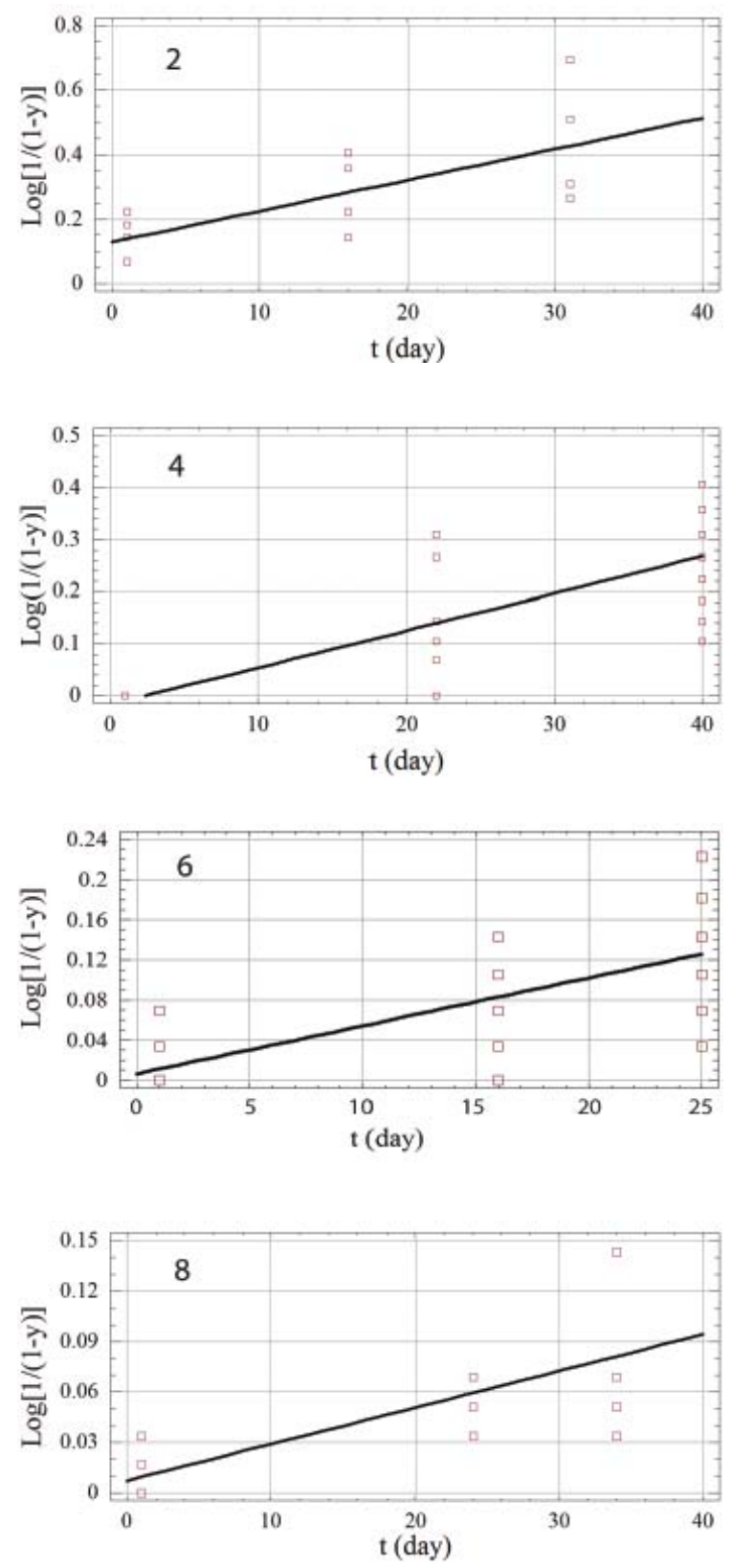

Figure 4. The linearized models for stem rot disease incidence progress in eight peanut fields (1-8) based on 2014 data. y: stem rot incidence; t: time (day) after first evaluation. 
Table 3. Stem rot disease progress model for different plots of field 1 based on 2014 data.

\begin{tabular}{l|c|c|c}
\hline Plot & Progress model & $\mathrm{R}^{2}(\%)$ & $\mathrm{SE}$ \\
\hline 1 & $\ln [1 /(1-\mathrm{y})]=-0.0289+0.0108^{*} \mathrm{t}$ & 97.96 & 0.0464 \\
2 & $\ln [1 /(1-\mathrm{y})]=0.0167+0.0079^{*} \mathrm{t}$ & 80.89 & 0.1141 \\
3 & $\ln [1 /(1-\mathrm{y})]=-0.0485+0.0148^{*} \mathrm{t}$ & 96.30 & 0.0865 \\
4 & $\ln [1 /(1-\mathrm{y})]=-0.0302+0.0198^{*} \mathrm{t}$ & 99.80 & 0.0265 \\
5 & $\ln [1 /(1-\mathrm{y})]=-0.1449+0.0235^{*} \mathrm{t}$ & 83.45 & 0.3121 \\
6 & $\ln [1 /(1-\mathrm{y})]=-0.0615+0.0148^{*} \mathrm{t}$ & 93.12 & 0.1200 \\
7 & $\ln [1 /(1-\mathrm{y})]=0.213+0.0097^{*} \mathrm{t}$ & 92.92 & 0.0800 \\
8 & $\ln [1 /(1-\mathrm{y})]=-0.0127+0.0122^{*} \mathrm{t}$ & 99.99 & 0.0015 \\
9 & $\ln [1 /(1-\mathrm{y})]=-0.0135+0.0074^{*} \mathrm{t}$ & 99.48 & 0.0157 \\
10 & $\ln [1 /(1-\mathrm{y})]=-0.163+0.026^{*} \mathrm{t}$ & 82.54 & 0.3528 \\
11 & $\ln [1 /(1-\mathrm{y})]=-0.057+0.0084^{*} \mathrm{t}$ & 79.90 & 0.1248 \\
12 & $\ln [1 /(1-\mathrm{y})]=-0.0608+0.0217^{* \mathrm{t}}$ & 97.62 & 0.1006 \\
13 & $\ln [1 /(1-\mathrm{y})]=-0.0095+0.0135^{*} \mathrm{t}$ & 99.93 & 0.0102 \\
14 & $\ln [1 /(1-\mathrm{y})]=0.0404+0.0200^{*} \mathrm{t}$ & 93.62 & 0.1555 \\
15 & $\ln [1 /(1-\mathrm{y})]=0.0190+0.0095^{*} \mathrm{t}$ & 93.71 & 0.0738 \\
16 & $\ln [1 /(1-\mathrm{y})]=-0.01953+0.0545^{*} \mathrm{t}$ & 95.00 & 0.3624 \\
17 & $\ln [1 /(1-\mathrm{y})]=0.0606+0.0151^{*} \mathrm{t}$ & 84.20 & 0.1948 \\
18 & $\ln [1 /(1-\mathrm{y})]=-0.0192+0.0096^{*} \mathrm{t}$ & 99.26 & 0.0245 \\
19 & $\ln [1 /(1-\mathrm{y})]=-0.013+0.0121^{*} \mathrm{t}$ & 99.99 & 0.0015 \\
20 & $\ln [1 /(1-\mathrm{y})]=-0.0018+0.0025^{*} \mathrm{t}$ & 97.78 & 0.0112 \\
\hline
\end{tabular}

$y$ : stem rot incidence; $\mathrm{R}^{2}$ : coefficient of determination; SE: standard error; $t$ : time

er compared to the other fields and thus no model was applied to the data.

Mean of stem rot severity in the first evaluation of the fields 2, 6 and 7 in 2014 was $2.84 \%, 0.60 \%$ and $1.45 \%$, respectively (Fig. $5)$. The disease severity of these selected fields at harvest (final disease severity) was $16.20 \%, 5.90 \%$ and $10.56 \%$, respectively, although in field 7 , the final disease severity corresponded to that assessed in the middle of the growing season as the crop was harvested 3 days later (Fig. 5).

Modeling the disease severity in fields 2 and 6 showed that the monomolecular model had the ability to describe more than $88 \%$ of the data: $\ln [1 /(1-y)]=0.0048^{*} t+0.0312$ $\left(R^{2}=96.69\right)$ for field 2 and $\ln [1 /(1-y)]=0.0018^{*} t-$ $0.00047\left(R^{2}=88.48\right)$ for field 6 (data not shown). In field 7, the crop was harvested 3 days after the second evaluation of the disease and thus no model was fitted to the data, as only two sets of data were collected.

\section{Effect of soil inoculum density on dis- ease symptoms}

Viable sclerotia were detected in the soil of 8 out of the 15 experimental fields in 2014, with fields 1 and 8 showing the highest and the lowest final disease incidence, respectively (Table 2 ). There was a significant $(P \leq 0.01)$ linear relationship between the final disease incidence (DI) and soil inoculum density (Fig. 6), which fitted to the model: $\mathrm{DI}=0.0419+0.0908^{*} \mathrm{Q}\left(\mathrm{R}^{2}=78.72\right)$, where $\mathrm{Q}$ is the number of viable sclerotia in $500 \mathrm{~g}$ dried soil. 
Table 4. Stem rot disease progress model for each peanut field based on the mean disease incidence in the plots at each evaluation time in 2013 and 2014.

\begin{tabular}{|c|c|c|c|c|c|}
\hline Field & Village & Year & Progress model & $\mathrm{R}^{2}(\%)$ & SE \\
\hline \multirow[t]{2}{*}{1} & \multirow[t]{2}{*}{ Noghredeh } & 2013 & $\ln [1 /(1-y)]=-0.0172+0.0054^{*} t$ & 88.90 & 0.0802 \\
\hline & & 2014 & $\ln [1 /(1-y)]=-0.0248+0.0145^{*} t$ & 99.33 & 0.0344 \\
\hline \multirow[t]{2}{*}{2} & \multirow[t]{2}{*}{ Noghredeh } & 2013 & $\ln [1 /(1-y)]=-0.0007+0.0026^{*} t$ & 78.46 & 0.0586 \\
\hline & & 2014 & $\ln [1 /(1-y)]=0.0876+0.0067^{*} t$ & 99.59 & 0.0091 \\
\hline \multirow[t]{2}{*}{3} & \multirow[t]{2}{*}{ Noghredeh } & 2013 & $\ln [1 /(1-y)]=-0.0244+0.0040^{*} t$ & 74.27 & 0.0800 \\
\hline & & 2014 & $\ln [1 /(1-y)]=0.0045+0.0055^{*} t$ & 91.12 & 0.0357 \\
\hline \multirow[t]{2}{*}{4} & \multirow[t]{2}{*}{ Noghredeh } & 2013 & $(-)$ & $(-)$ & $(-)$ \\
\hline & & 2014 & $\ln [1 /(1-y)]=-0.005+0.0038^{*} t$ & 99.91 & 0.0032 \\
\hline \multirow[t]{2}{*}{5} & \multirow[t]{2}{*}{ Noghredeh } & 2013 & $\ln [1 /(1-y)]=0.00015+0.0017^{*} t$ & 89.99 & 0.0206 \\
\hline & & 2014 & $\ln [1 /(1-y)]=0.0444+0.0038^{*} t$ & 93.15 & 0.0180 \\
\hline \multirow[t]{2}{*}{6} & \multirow[t]{2}{*}{ Noghredeh } & 2013 & $\ln [1 /(1-y)]=0.0223+0.00047^{*} t$ & 86.64 & 0.0080 \\
\hline & & 2014 & $\ln [1 /(1-y)]=0.0181+0.0031^{*} t$ & 98.12 & 0.0102 \\
\hline \multirow[t]{2}{*}{7} & \multirow[t]{2}{*}{ Noghredeh } & 2013 & $\ln [1 /(1-y)]=0.0264+0.0055^{*} t$ & 88.14 & 0.0730 \\
\hline & & 2014 & $\ln [1 /(1-y)]=-0.0054+0.0031^{*} t$ & 99.70 & 0.0053 \\
\hline \multirow[t]{2}{*}{8} & \multirow[t]{2}{*}{ Salestan } & 2013 & $\ln [1 /(1-y)]=-0.0116+0.0013^{*} t$ & 77.50 & 0.0287 \\
\hline & & 2014 & $\ln [1 /(1-y)]=-0.0014+0.0028^{*} t$ & 96.37 & 0.0132 \\
\hline \multirow[t]{2}{*}{9} & \multirow[t]{2}{*}{ Salestan } & 2013 & $\ln [1 /(1-y)]=-0.0121+0.0012 * t$ & 73.33 & 0.0304 \\
\hline & & 2014 & $\ln [1 /(1-y)]=0.0052+0.00108^{*} t$ & 61.77 & 0.0203 \\
\hline \multirow[t]{2}{*}{10} & \multirow[t]{2}{*}{ Khoshkarvandan } & 2013 & Zero incidence & & \\
\hline & & 2014 & Zero incidence & & \\
\hline \multirow[t]{2}{*}{11} & \multirow[t]{2}{*}{ Khoshkarvandan } & 2013 & $\ln [1 /(1-y)]=0.0016+0.00105^{*} t$ & 51.63 & 0.0395 \\
\hline & & 2014 & $\ln [1 /(1-y)]=0.0019+0.0007^{*} t$ & 97.40 & 0.0032 \\
\hline \multirow[t]{2}{*}{12} & \multirow[t]{2}{*}{ Khoshkarvandan } & 2013 & $\ln [1 /(1-y)]=-0.0056+0.0007^{*} t$ & 67.97 & 0.0193 \\
\hline & & 2014 & $\ln [1 /(1-y)]=0.0069+0.00076^{*} t$ & 93.84 & 0.0042 \\
\hline \multirow[t]{2}{*}{13} & \multirow[t]{2}{*}{ Khoshkarvandan } & 2013 & $\ln [1 /(1-y)]=0.0141+0.0017^{*} \mathrm{t}$ & 93.60 & 0.0194 \\
\hline & & 2014 & $\ln [1 /(1-y)]=0.0214+0.0009 * t$ & 97.73 & 0.0043 \\
\hline \multirow[t]{2}{*}{14} & \multirow[t]{2}{*}{ Noghredeh } & 2013 & $\ln [1 /(1-y)]=-0.0194+0.0036^{*} t$ & 79.97 & 0.0618 \\
\hline & & 2014 & $\ln [1 /(1-y)]=-0.0153+0.0056^{*} t$ & 97.56 & 0.0260 \\
\hline \multirow[t]{2}{*}{15} & \multirow[t]{2}{*}{ Noghredeh } & 2013 & $\ln [1 /(1-y)]=-0.0119+0.0030 * t$ & 88.58 & 0.0367 \\
\hline & & 2014 & $\ln [1 /(1-y)]=-0.0011+0.0016^{*} t$ & 87.16 & 0.0148 \\
\hline
\end{tabular}

$y$ :stem rot incidence; $R^{2}$ : coefficient of determination; SE: standard error; t: time; (-): no model was fitted to the data because only two disease assessments were done.

There was also a significant linear relationship between the soil inoculum density and disease growth rate, which fitted to the model: $r_{m}=0.0043+0.0024^{*} \mathrm{Q}\left(R^{2}=76.72\right)$, where $r_{m}$ is the disease growth rate and $Q$ is the number of viable sclerotia / $500 \mathrm{~g}$ dried soil (Fig. 7). Based on this model, the effective factor (R) for the monomolecular mod- el is equal to 0.0024 that shows the impact of the environment, host, etc. on the disease development. A positive linear relationship was also observed between the final disease severity (DS) and the number of viable sclerotia / $500 \mathrm{~g}$ dried soil for fields 2, 6 and 7, where the disease severity was evaluated in 2014 (Fig. 8). The number of viable sclerotia / 


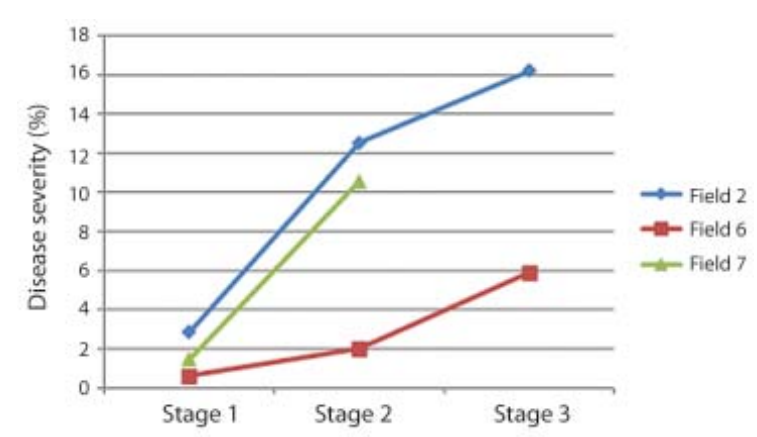

Figure 5. Stem rot disease progress for three peanut fields based on the severity data in 2014. Stage 1: Beginning of the growing season; Stage 2: Middle of the growing season (anthesis stage); Stage 3: Harvest time.

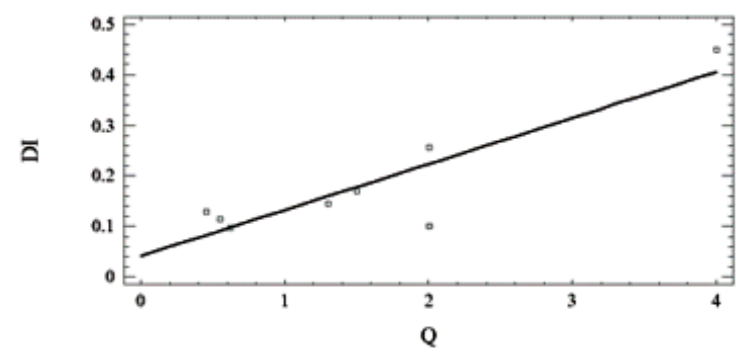

Figure 6. Linear relationship between the number of viable sclerotia and the stem rot incidence in eight evaluated peanut fields in 2014. DI: Disease incidence at harvest time (based on 0-1); Q: Number of viable sclerotia / $500 \mathrm{~g}$ dried soil.

$500 \mathrm{~g}$ dried soil was $2,0.55$ and 0.45 and the final DS was $16.20 \%, 5.90 \%$ and $10.56 \%$ for the fields 2, 6 and 7, respectively. The data fitted to the model: $\mathrm{DS}=0.0575+0.0514^{*} \mathrm{Q}$ $\left(R^{2}=74.76\right)$.

\section{Discussion}

As noted above, the lowest and the highest number of viable sclerotia were counted in the fields 6 and 1, respectively. The final disease incidence in the 15 peanut fields studied at the present study varied between $0-29.3 \%$ and $0-45 \%$ in 2013 and 2014, respectively. Okabe and Matsumuto (2000) reported that the stem rot disease incidence in peanut fields in Japan ranged between 10 and 40\% during the period 1994-1997. According to Le et al. (2012), the disease incidence in peanut fields of eight regions in

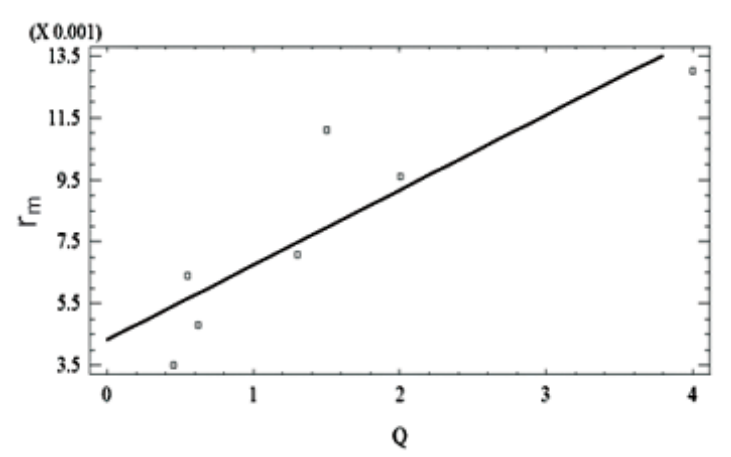

Figure 7. Linear relationship between the number of viable sclerotia and the disease growth rate in eight evaluated peanut fields in 2014. $\mathrm{r}_{\mathrm{m}}$ : Disease growth rate (multiply at 0.001 ); Q: Number of viable sclerotia / $500 \mathrm{~g}$ dried soil.

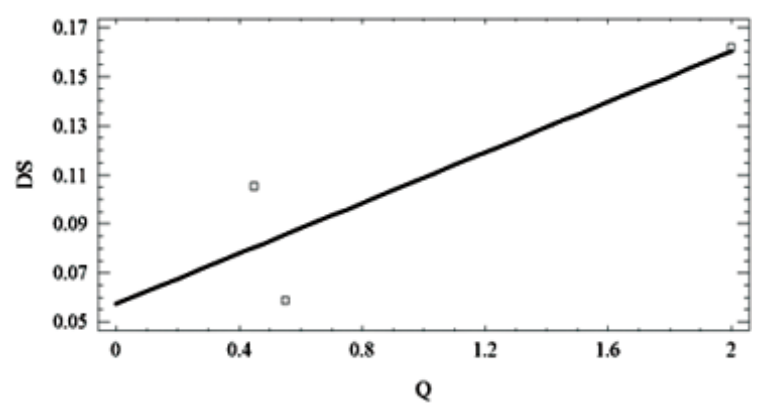

Figure 8. Linear relationship between the number of viable sclerotia and the disease severity in eight evaluated peanut fields in 2014. DS: Disease severity at harvest time (based on 0-1); Q: Number of viable sclerotia / 500 g dried soil.

Vietnam was $5-25 \%$.

The disease progress model introduced in the current study for each field based on the mean disease incidence in the plots in each evaluation time point in 2013 and 2014 showed good fitness with the monomolecular model in both years, but especially in 2014. The disease growth rate in 7 fields was higher in 2014 than in 2013. There was a significant $(P \leq 0.01)$ linear relationship between the final disease incidence and the inoculum density in the soil and between the inoculum density and the disease growth rate.

Backman et al. (1981) estimated the number of viable sclerotia of $A$. rolfsii in soil samples from sugar beet (Beta vulgaris L.) fields to predict the stem rot incidence in the following season and reported 0-36 viable sclerotia in $500 \mathrm{~g}$ dried soil samples based on soiltray technique. They reported a significant linear relationship between inoculum den- 
sity and infected sugar beet plants $(P \leq 0.01)$ and stated that the disease can be forecasted based on this model. They declared that one viable sclerotium in $500 \mathrm{~g}$ dried soil is nearly equivalent with $1 \%$ disease incidence at harvest time. Punja (1986) reported a relationship between the disease incidence and inoculum density for carrot fields. Based on his study, there was a linear increase in disease incidence related to inoculum population increment from 0 to15 viable sclerotia / $300 \mathrm{~cm}^{3}$ dried soil; in addition, the number of the dead plants was significantly $(P \leq 0.05)$ related to inoculum density.

Tomasino and Conway (1987) identified a positive linear relationship between inoculum density and disease incidence on apple roots in Oklahoma and stated that 5 viable sclerotia / $1000 \mathrm{~g}$ dried soil resulted in 19, 5 and 35\% disease incidence in pot, micro-plot and field studies, respectively.

Because of the low precipitation in the 2014 peanut growing season in AstanehAshrafiyeh, the farmers had to harvest the crop 7-10 days earlier for preventing yield loss. As a result, the final evaluation of the disease incidence was done 8 days earlier than in 2013. Although the final evaluation of the disease incidence was done earlier in 2014 compared with 2013, the mean of the final disease incidences in both years were approximately the same (i.e., $12.88 \%$ for 2013 and $12.90 \%$ for 2014).

Based on the results of the study conducted by Bowen (2003) in Alabama, the higher than the normal amount of precipitation during the growing season and the higher than the field capacity soil moisture lead to decreased stem rot disease incidence. Punja (1986) also considered the increased soil moisture as an inhibiting factor for mycelial growth of $A$. rolfsii. In the current study and based on the weather data, the consecutive rainfall occurred in June and July 2013 compared with the rarely rainy weather during the same period in 2014 resulted in increased field capacity and to some extent decreased disease incidence.

As shown in the present study, the inoculum densities in fields 2 and 8 were equal.
However, the final disease incidences in these two fields were not the same. This difference could be related to different soil textures in these fields. Punja and Jenkins (1984) reported that the stem rot disease incidence is higher in sandy soils compared to loamy or clay soils. The second factor could be the plant density, as field 2 was more densely populated and resulted in a faster plant to plant spread of the disease compared to field 8. In densely populated fields, even few foci can lead to high disease incidence (Punja, 1986). Sconyers et al. (2007) investigated the effect of cropping pattern on the stem rot distribution in peanut fields and reported that the physical distance among the plants is a critical factor in disease development.

In the current study, during the first evaluation of field 2, infection was observed in $70 \%$ of the studied plots whereas, only $44 \%$ of the plots in field 6 were infected. Punja (1986) pointed to the importance of disease foci in the stem rot incidence during the next growing season. In the present study, the high number of disease foci in field 2 at the beginning of the growing season may have resulted in higher disease severity during the first evaluation. However, the final disease severity in field 2 was 5.7fold of that at the beginning of the growing season, whereas in filed 6, it was 9.8fold. It seems that the drought stress related to the soil texture in field 6 was responsible for the increase in disease severity during the growing season. Although higher numbers of viable sclerotia were counted in field 6 compared to field 7, field 6 showed lower disease severity at harvest time. Soil texture and plant density as well as simultaneous cultivation of two hosts of $A$. rolfsii (bean and peanut in field 7) are probably responsible for this difference. This is the first time that the stem rot severity progress has been studied under field conditions.

The authors would like to thank University of Guilan (Deputy of Research) for its important technical support. 


\section{Literature Cited}

Aycock, R. 1966. Stem rot and other diseases caused by Sclerotium rolfsii. North Carolina Agricultural Experiment Station Bulletin, 174: 202.

Backman, P.A., Rodriguez-Kabana, R., Caulin, M.C., Beltramini, E. and Ziliani, N. 1981. Using the soiltray technique to predict the incidence of Sclerotium rot in sugar beets. Plant Disease, 65: 419421.

Bowen, K.L. 2003. Development of stem rot (caused by Sclerotium rolfsii) in peanut in Alabama. Peanut Science, 30 (2): 120-128.

Eslami, A.A., Khodaparast, S.A., Mousanejad, S. and Padasht Dehkaei, F. 2015. Evaluation of the virulence of Sclerotium rolfsii isolates on Arachis hypogaea and screening for resistant genotypes in greenhouse conditions. Hellenic Plant Protection Journal, 8: 1-11.

Fery, R.L. and Dukes, P.D. 2011. Southern blight (Sclerotium rolfsii Sacc.) of cowpea: Genetic characterization of two sources of resistance. International Journal of Agronomy, doi:10.1155/2011/652404.

Fery, R.L. and Dukes, P.D. 2005. Potential for utilization of pepper germplasm with a variable reaction to Sclerotium rolfsii Sacc. to develop southern blight resistant pepper (Capsicum annum L.) cultivars. Plant Genetic Resources: Characterization and Utilization, 3: 326-330.

Hammons, R.O. 1994. The origin and history of the groundnut. Pp. 56-78. In: The Groundnut Crop: A Scientific Basis for Improvement (Smartt, J., ed). Chapman and Hall, London.

Kokalis-Burelle, N., Porter, D.M., Rodriguez-Kabana, R., Smith, D.H. and Subrahmanyam, P. 1997. Compendium of Peanut Diseases. Second Edition. USA, APS Press.

Kolte, S.J. 1984. Diseases of Annual Edible Oilseed Crops. Vol. I. Peanut Diseases. Boca Raton, FL, CRC Press.

Lakpale, N., Khare, N. and Thrimurty, V.S. 2007. Suppression of Sclerotium rolfsii Sacc.: an intergrated approach. Soils and Crops, 17: 241-245.

Le, C.N. 2004. Study wilt diseases on groundnut and some methods to control them in Thua Thien Hue province. Vietnam National Journal of Plant Protection, 1: 9-15.

Le, C.N., Mendes, R., Kruijt, M. and Raaijmakers, J.M. 2012. Genetic and phenotypic diversity of Sclerotium rolfsii in groundnut fields in central Vietnam. Plant Disease, 96: 389-397.

Mehan, V.K., Mayee, C.D., McDonald, D., Ramakrishna, N. and Jayanthi, S. 1995. Resistance in groundnut to Sclerotium rolfsii caused stem and pod rots. International Journal of Pest Management, 41: 79-82.
Mullen, J. 2001. Southern blight, southern stem blight, white mold. The Plant Health Instructor, doi: 10.1094/PHI-I-2001-0104-01.

Nguyen, T.N., Tran, V.M., Nguyen, T.T. and Le, C.N. 2004. Research on groundnut diseases in Quang Binh province. National Agricultural Rural Development, 17: 337-342.

Okabe, I. and Matsumoto, N. 2000. Population structure of Sclerotium rolfsii in peanut fields. Mycoscience, 41: 145-148.

Punja, Z.K. 1986. Progression of root rot on processing carrots due to Sclerotium rolfsii and the relationship of disease incidence to inoculum density. Canadian Journal of Plant Pathology, 8(3): 297-304.

Punja, Z.K. 1985. The biology, ecology and control of Sclerotium rolfsii. Annual Review of Phytopathology, 23: 97-127.

Punja, Z.K. and Jenkins, S.F. 1984. Influence of temperature, moisture, modified gaseous atmosphere and depth in soil on eruptive sclerotial germination of Sclerotium rolfsii. Phytopathology, 74: 749-754.

Punja, Z.K., Smith, V.L., Campbell, C.L. and Jenkins, S.F. 1985. Sampling and extraction procedures to estimate numbers, spatial pattern, and temporal distribution of sclerotia of Sclerotium rolfsii in soil. Plant Disease, 69: 469-474.

Rodriguez-Kabana, R., Beute, M.K. and Backman, P.A. 1980. A method for estimating numbers of viable sclerotia of Sclerotium rolfsii in soil. Phytopathology, 70: 917-919.

Savage, G.P. and Keenan, J.I. 1994. The composition and nutritive value of groundnut kernels. Pp. 173-213. In: The Groundnut Crop: A Scientific Basis for Improvement (Smartt, J., ed). Chapman and Hall, London.

Sconyers, L.E., Brenneman, T.B., Stevenson, K.L. and Mullinix, B.G. 2007. Effects of row pattern, seeding rate, and inoculation date on fungicide efficacy and development of peanut stem rot. Plant Disease, 91: 273-278.

Shokes, F. and Gorbet, D. 1998. Crop losses due to stem rot of groundnut in commercial cultivars and partially resistant breeding lines. ICPP98 Paper No. 3. 4. 5.

Tomasino, S.F. and Conway, K.E. 1987. Spatial pattern, inoculum density-disease incidence relationship and population dynamics of Sclerotium rolfsii on apple rootstock. Plant Disease, 71: 719724.

Received: 12 August 2018; Accepted: 1 November 2021 


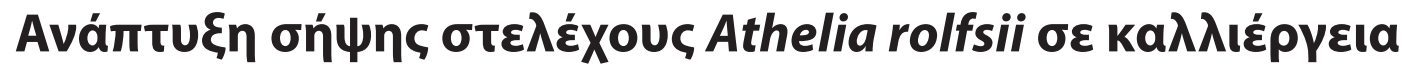 apaxídaç oto lpáv
}

\author{
Gh.A. Amirkyaei, S. Mousanejad, N. Safaie kaı S.A. Khodaparast
}

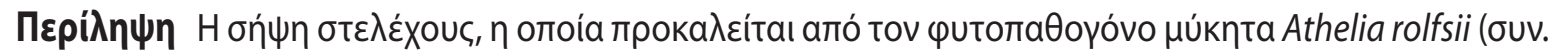

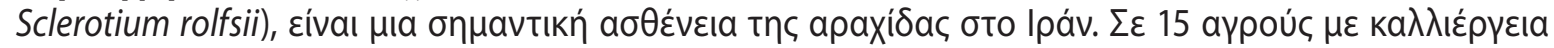

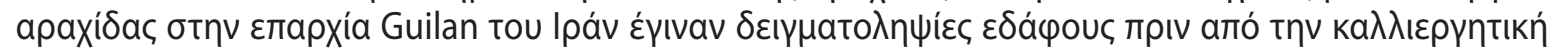

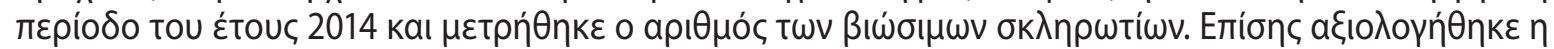

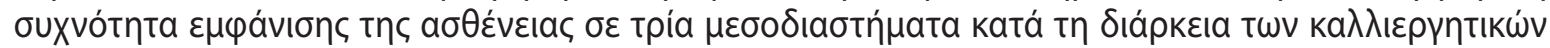

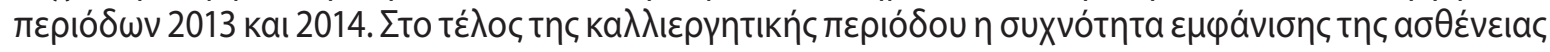

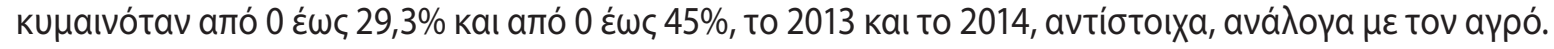

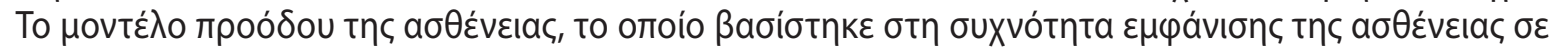

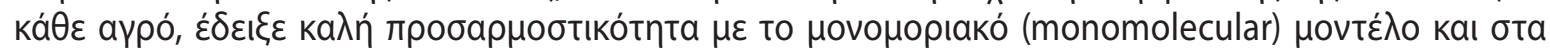

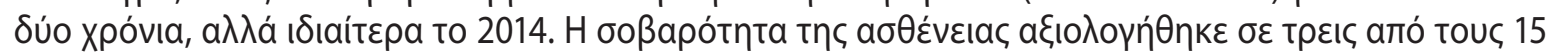

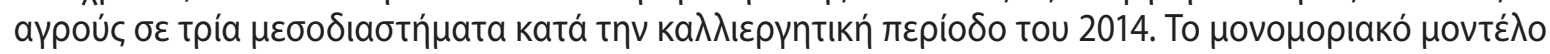

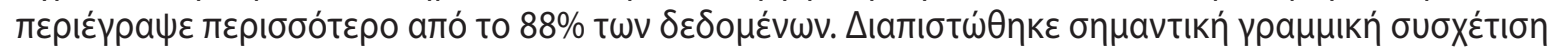

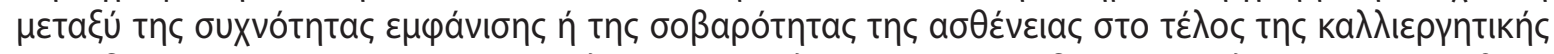

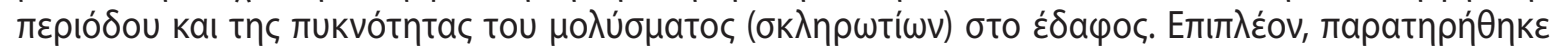

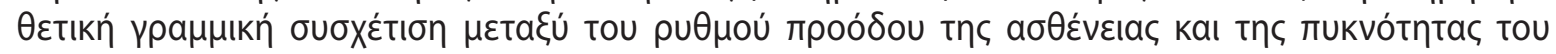

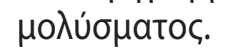

